\title{
A novel Fireworks Factor and Improved Elite Strategy based on Back Propagation Neural Networks for state-of-charge estimation of lithium-ion batteries
}

\author{
Xianpei Chen ${ }^{1}$, Shunli Wang ${ }^{1, *}$, Yanxing Xie ${ }^{1}$, Carlos Fernandez ${ }^{2}$, Yongcun Fan $^{1}$ \\ ${ }^{1}$ School of Information Engineering, Southwest University of Science and Technology, Mianyang \\ 621010, China; \\ ${ }^{2}$ School of Pharmacy and Life Sciences, Robert Gordon University, Aberdeen AB10-7GJ, UK. \\ *E-mail: wangshunli@swust.edu.cn
}

Received: 2 April 2021 / Accepted: 20 May 2021 / Published: 10 August 2021

\begin{abstract}
The state of charge (SOC) of Lithium-ion battery is one of the key parameters of the battery management system. In the SOC estimation algorithm, the Back Propagation (BP) neural network algorithm is easy to converge to the local optimal solution, which leads to the problem of low accuracy based on the BP network. It is proposed that the Fireworks Elite Genetic Algorithm (FEG-BP) is used to optimize the BP neural network, which can not only solve the problem of the traditional neural network algorithm that is easy to fall into the local maximum optimal solution but also solve the limitation of the traditional neural network algorithm. The searchability of the improved algorithm has been significantly enhanced, and the error has become smaller and the propagation speed is faster. Combining the experimental data of charging and discharging, the proposed FEG-BP neural network is compared with the traditional genetic neural network algorithm (GA-BP), and the results are analyzed. The results show that the standard BP neural network genetic algorithm predicts error within 7\%, while FEG-BP reduces the error to within $3 \%$.
\end{abstract}

Keywords: Lithium-ion battery; State of charge; Genetic algorithm; Back Propagation; SOC estimation

\section{$\underline{\text { FULL TEXT }}$}

(C) 2021 The Authors. Published by ESG (www.electrochemsci.org). This article is an open access article distributed under the terms and conditions of the Creative Commons Attribution license (http://creativecommons.org/licenses/by/4.0/). 